\title{
PLACAS DE CIRCUITO IMPRESSO: CARACTERIZAÇÃO E VALOR AGREGADO
}

\author{
Marcos Paulo Kohler Caldas 1,2 \\ Bárbara Mazzini Loureiro ${ }^{3}$ \\ Flávia Paulucci Cianga Silvas ${ }^{4}$ \\ Viviane Tavares de Moraes ${ }^{5}$ \\ Jorge Alberto Soares Tenório ${ }^{6}$ \\ Denise Crocce Romano Espinosa ${ }^{6}$
}

\section{Resumo}

Esse trabalho tem o propósito de caracterizar quatro lotes diferentes de placas de circuito impresso (PCls) do mercado de sucatas identificando e quantificando os metais presentes para assim relacionar ao valor associado a cada um dos lotes. Para alcançar o objetivo proposto realizou-se cominuição em moinho de facas, seguido de análise em estereoscópio para verificar a liberação dos metais. Em seguida foram testadas duas rotas de lixiviação ácida para caracterização da fração metálica: lixiviação em água régia, seguida de lixiviação em ácido nítrico e também lixiviação em água régia invertida. As análises químicas quantitativas foram feitas por ICP-OES e também se realizou ensaios de perda ao fogo para quantificar as frações polimérica e cerâmica. Encontrou-se para o lote A 33,6\% de material metálico, $42,01 \%$ no lote B, 24,27\% no lote $C$ e 26,04 no lote $D$. O metal mais abundante em todos os lotes foi o cobre e foram encontradas porcentagens de ouro com alto valor associado. Para $100 \%$ dos metais recuperados nos lotes estudados seria possível obter para o lote A 27.643,42 dólares, para o lote B 8.585,22 dólares, para o lote $C$ 10.187,76 dólares e para o lote D 6.409, 17 dólares por tonelada. A diferença entre os valores dos lotes, que pode chegar a 21.234,25 dólares quando comparados A e D justifica uma melhor analise das placas, com posterior separação por tipo, antes da venda às indústrias recicladoras.

Palavras-chave: PCls; Reciclagem; Caracterização; Valor econômico.

\section{PRINTED CIRCUIT BOARDS: CHARACTERIZATION AND ADDED VALUE.}

\begin{abstract}
This work has the purpose of characterizing four different lots of printed circuit boards (PCBs) of the scrap market, identifying and quantifying metals in them to establish a relation with the value associated with each of the lots. To achieve the proposed objective, comminution was performed in a cutting mill, followed by analysis in stereoscope to verify the release of metals. Subsequently, two routes of acid leaching for metal fraction characterization were tested: leaching in aqua regia, followed by leaching in nitric acid and also leaching in inverse aqua regia. The quantitative chemical analyses were performed by ICP-OES, and loss on ignition was also performed to quantify the polymer and ceramic fractions. For lot A, $33.6 \%$ of metal material was found, $42.01 \%$ for lot B, $24.27 \%$ for lot C, and 26.04 for lot D. The most abundant metal in all the lots was copper, and percentages of gold with high associated value were found. Considering $100 \%$ of the metal recovered in the studied lots, a sum of 27,643.42 USD could be obtained for lot A, 8,585.22 USD for lot $B$, I0, I87.76 USD for lot $C$, and 6,409.17 USD for lot D, per ton of PCB. The difference between the values of the lots, which can reach 2 I ,234.25 USD when A and D are compared, justifies a better analysis of the plates, with subsequent separation by type, before the sale to the recycling industries.

Keywords: PCBs; Recycling; Characterization; Economic value.

\footnotetext{
'Departamento de Engenharia Química, Escola Politécnica, Universidade de São Paulo - USP, São Paulo, SP, Brasil. E-mail: marcospaulo@ifes.edu.br ${ }^{2}$ Instituto Federal de Ciência, Educação e Tecnologia do Espírito Santo - IFES, Serra, ES, Brasil.

${ }^{3}$ Departamento de Engenharia Metalúrgica e de Materiais, Universidade de São Paulo - USP, São Paulo, SP, Brasil.

${ }^{4}$ Instituto Tecnológico da Vale - ITV, Ouro Preto, MG, Brasil.

${ }^{5}$ Centro Universitário, Instituto Mauá de Tecnologia, São Caetano do Sul, SP, Brasil.

${ }^{6}$ Departamento de Engenharia Química, Universidade de São Paulo - USP, SP, Brasil.
}

2176-1523 (C) 2019 Associação Brasileira de Metalurgia, Materiais e Mineração. Publicado pela ABM. Este é um artigo de acesso aberto distribuído sob os termos da licença Creative Commons CC BY-NC-ND (Attribution-NonCommercial-NoDerivs) - https:// creativecommons.org/licenses/by-nc-nd/4.0\%. 


\section{INTRODUÇÃO}

A tecnologia está evoluindo de forma acelerada e com isso o ciclo de vida dos equipamentos eletroeletrônicos vem diminuindo. Rapidamente os modelos e configurações de computadores, celulares, televisões e impressoras, por exemplo, se tornam obsoletos e são descartados [I]. Estima-se que em 2016 foram produzidas 44,7 milhões de toneladas de resíduos eletroeletrônicos (REEEs) [2,3]. Nesse mesmo ano o Brasil produziu I,5 milhão de toneladas de REEE, ou seja, 7,2 kg per capita [3,4].

A matéria prima utilizada na produção dos equipamentos é, em geral, obtida a partir de fontes não renováveis. Contudo, com o passar das décadas, os teores de metal presentes nos minérios tem diminuído, tornando cada vez mais caro a mineração e obtenção destes elementos o que reforça a importância da reciclagem desses equipamentos e a recuperação dos materiais neles presentes. Além disso, a disposição inadequada pode trazer vários riscos tanto para a população quanto para o meio ambiente, pois envolve materiais perigosos e tóxicos [5]. Faz parte do desenvolvimento socioambiental de um país a atenção com seus resíduos. Através de diversos estudos percebe-se que são muitos os benefícios que essa política pode trazer em um mundo onde um dos conceitos mais falados e procurados é a sustentabilidade [6-I I].

Uma parte dos REEEs de grande interesse econômico de reciclagem são as placas de circuito impresso $(\mathrm{PCls})$, onde se encontra a maior fração metálica. Elas contêm partes tanto inorgânicas como orgânicas e uma grande variedade de metais de interesse em recuperação, como $\mathrm{Cu}, \mathrm{Au}, \mathrm{Al}, \mathrm{Sn}$, entre outros [I]. Porém, as PCls são extremamente heterogêneas, variando sua composição tanto em relação a sua aplicação, como fabricantes e tecnologia empregada. Isso influencia diretamente ao valor econômico associado a cada tipo de placa, e, portanto, ao seu comércio [12].
A coleta e separação dessas placas dentre o lixo convencional não costuma ser feita pelo próprio consumidor e, nessa etapa, que aparece o papel dos sucateiros, pessoas que recuperam esses materiais junto ás assistências técnicas, centros de coletas e aterros. É nesse momento que acontece a separação das placas de acordo com seu valor associado, e se torna de extrema importância a caracterização delas. Os sucateiros vendem em geral em lotes as PCls para empresas recicladoras, a fim de aprimorar o processo de recuperação e o seu ganho [3].

O objetivo desse trabalho é caracterizar quatro lotes encontrados no mercado de sucatas de PCls a fim de identificar e quantificar os metais presentes em cada um deles. Pretende-se também relacionar os dados encontrados com seus valores de mercado, justificando sua importância e sua separação.

\section{MATERIAIS E MÉTODOS}

\section{I Materiais}

Foram separados para caracterização quatro lotes de placas de circuito impresso. Cada lote se caracteriza pela presença de um ou mais tipos de placas de circuito impresso de computadores obsoletos. O lote A é composto de: memória dourada, processador slot e placas de HD (Figura I). O lote $\mathrm{B}$ refere-se a placas mãe de computador antigas (Figura 2), o lote $C$ placas de circuito impresso provenientes de equipamentos diversos como impressoras e computadores obsoletos (Figura 3) e o lote D placas ponteiras (Figura 4). Essa separação e nomenclatura são feitas usualmente na indústria e usada no mercado de compra e venda de REEE e relaciona-se ao valor associado a cada tipo placa.

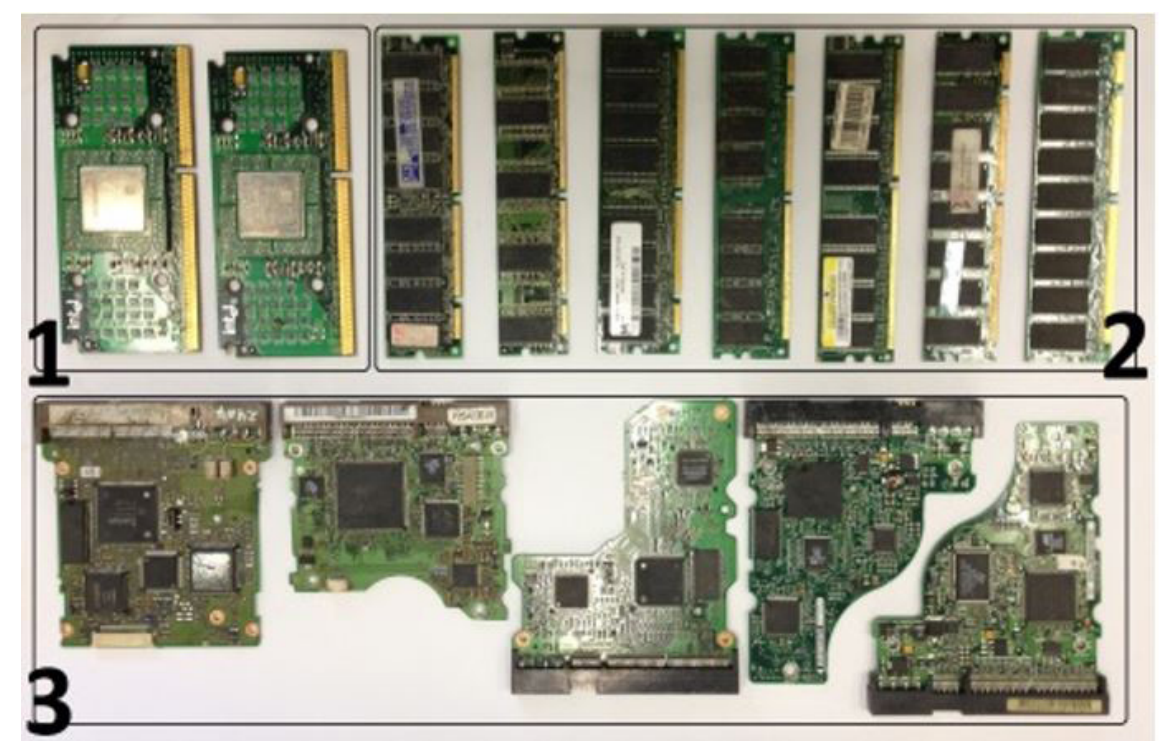

Figura I. Lote A. I-Memória dourada; 2-Procesador slot; 3-Placas de HD. 
Para processamento mecânico foram utilizados aproximadamente 300 gramas de cada lote. As PCls foram cominuídas em um moinho de facas, passando sequencialmente a amostra por grelhas de $9 \mathrm{~mm}, 6 \mathrm{~mm}$ e $3 \mathrm{~mm}$.
Após a cominuição os lotes foram analisados em estereoscópio para verificar a liberação dos materiais presentes nas placas. Em seguida foram feitas duas rotas de lixiviação ácida: digestão em água régia [8] seguida de

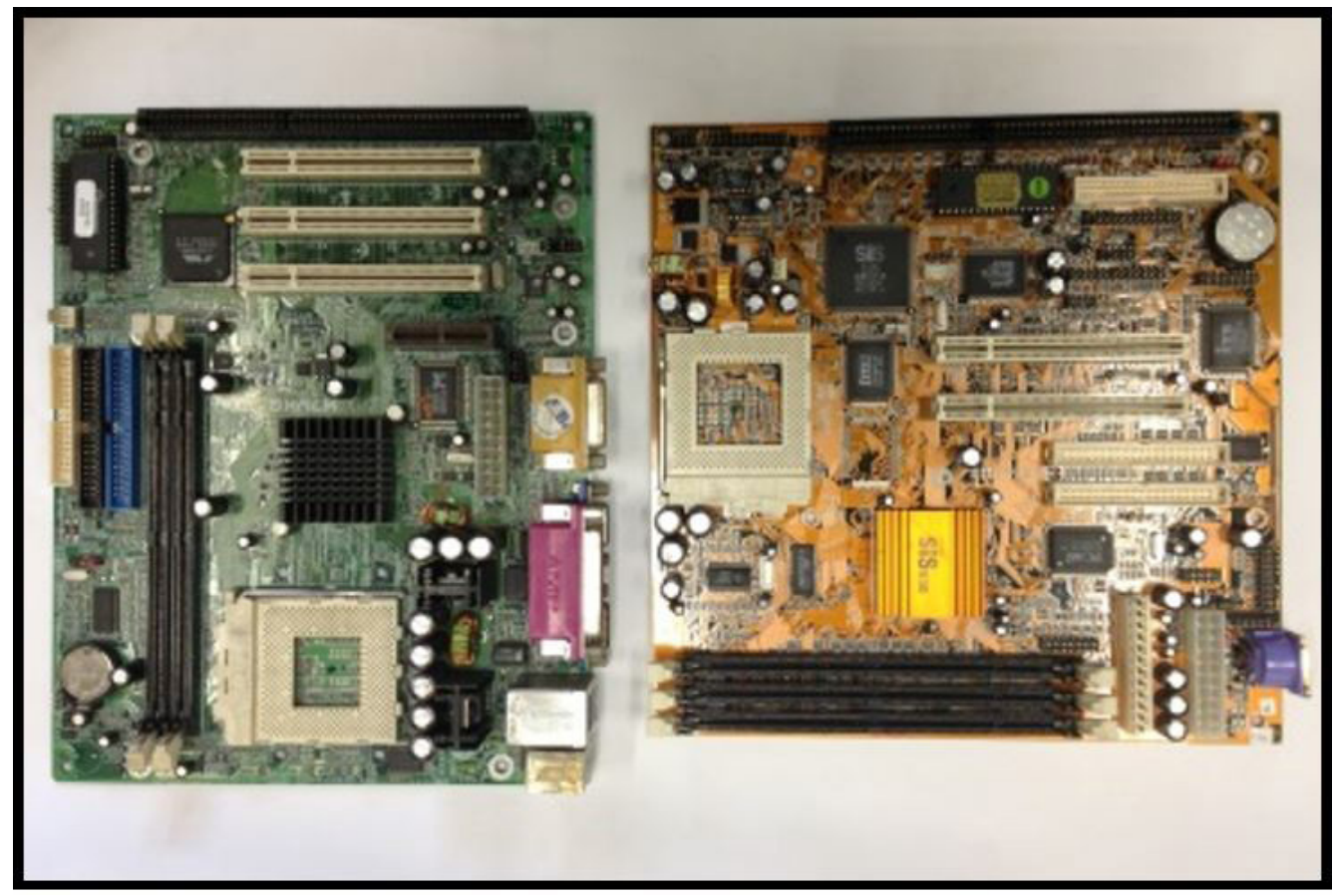

Figura 2. Lote B. Placas mãe antigas.

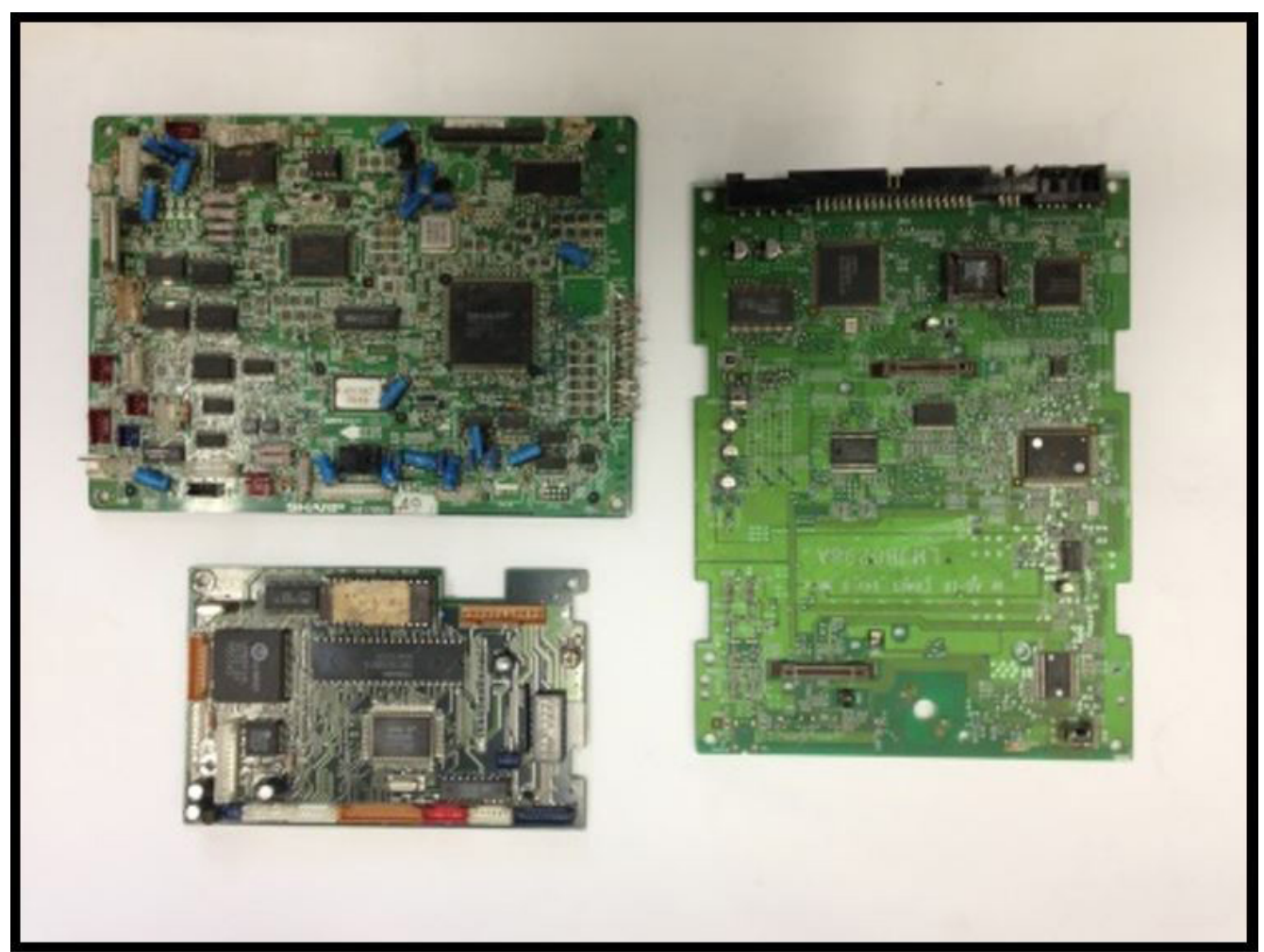

Figura 3. Lote C. Placas diversas. 
lixiviação com ácido nítrico 10 M [13] e água régia invertida. Esses procedimentos foram realizados para garantir que todo o metal presente nas PCls fossem solubilizados e posteriormente quantificados. Os filtrados da primeira sequência de lixiviação passaram por ensaio de perda ao fogo para quantificar as frações cerâmica e polimérica de cada lote, fechando assim o balanço de massa [8] A análise química quantitativa foi feita por ICP-OES. A sequência utilizada está ilustrada no fluxograma do processo (Figura 5).

\subsection{Análise no Esteroscópio}

As amostras após passarem pelo processo de cominuição foram observadas em estereoscópio a fim de verificar a liberação dos materiais e, assim, garantir que a fração metálica fosse solubilizada durante a lixiviação ácida.

\subsection{Lixiviação Ácida das Pcis}

\subsection{Caracterização com água régia}

Separou-se para lixiviação em água régia aproximadamente $5 \mathrm{~g}$ de cada lote por quarteamento. Utilizou-se uma proporção de $\mathrm{I}: 20,20 \mathrm{ml}$ de água régia para cada Ig de amostra [7]. A solução permaneceu durante $24 \mathrm{~h}$ a temperatura ambiente $\left(25^{\circ} \mathrm{C}\right)$, para completa digestão dos metais. As próximas etapas foram filtração em papel de filtro quantitativo seguido de análise do líquor por Espectrometria de Emissão Atômica por Plasma Acoplado (ICP-OES) visando quantificar os metais presentes.

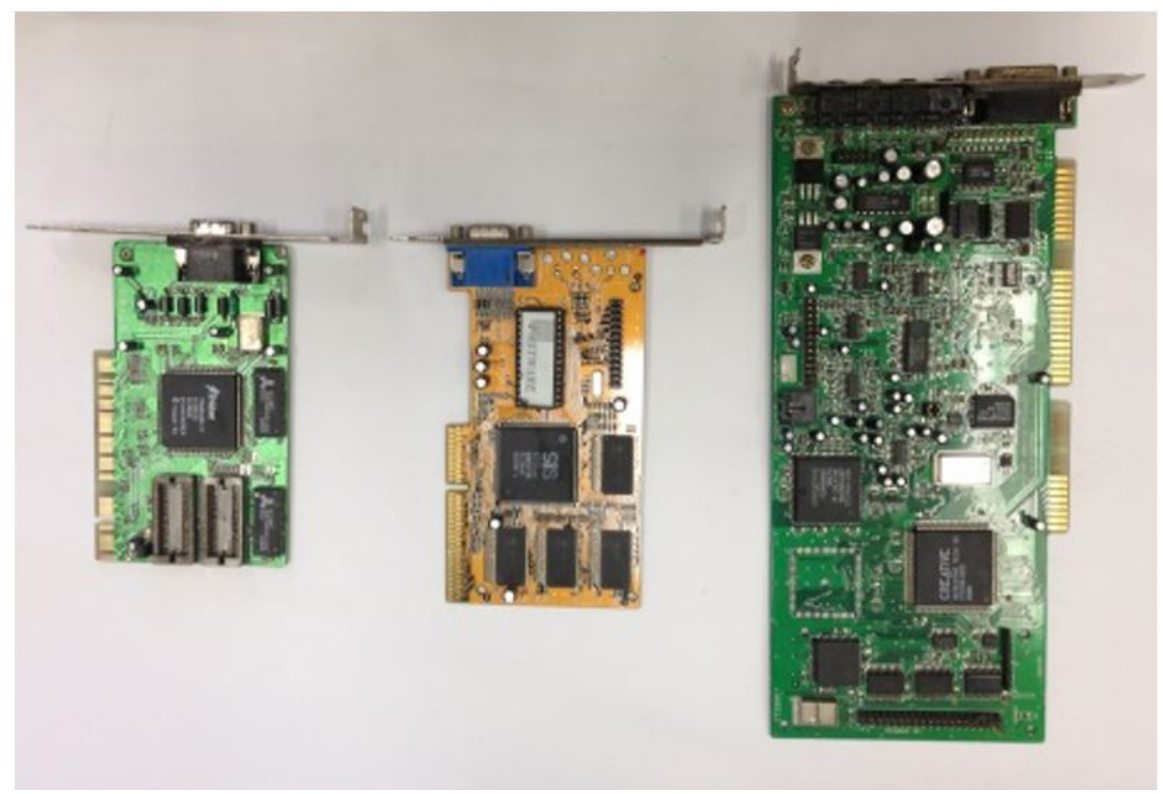

Figura 4. Lote D. Placas ponteiras.

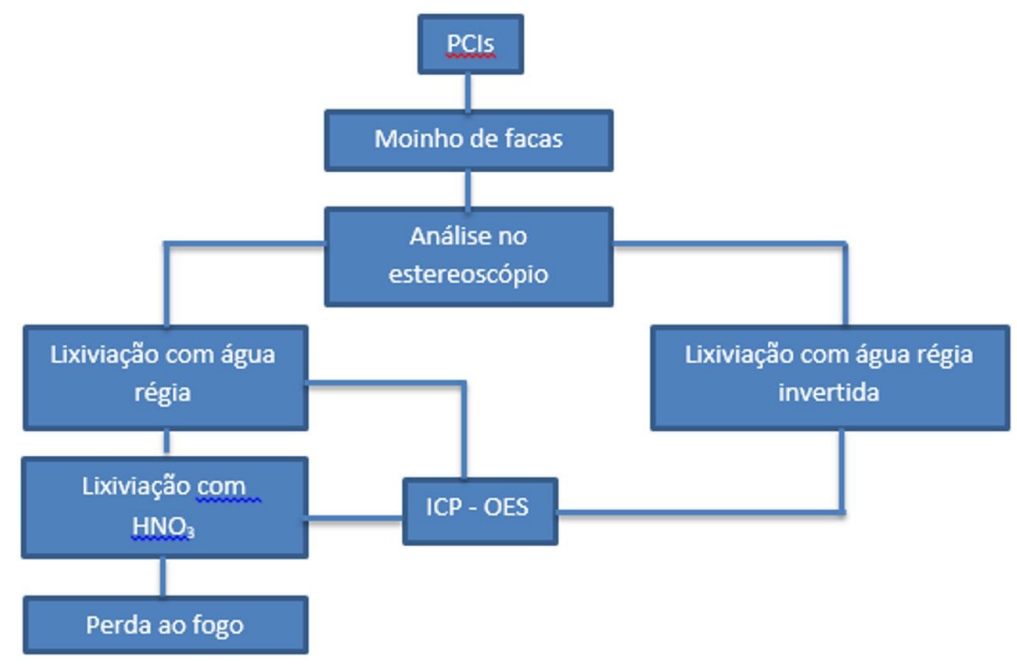

Figura 5. Fluxograma do processo. 


\subsubsection{Lixiviação com $\mathrm{HNO}_{3}$}

Os sólidos filtrados na etapa de lixiviação em água régia foram colocados em ácido nítrico IOM durante $2 \mathrm{~h}$ em temperatura ambiente $\left(25^{\circ} \mathrm{C}\right)$ na proporção $\mathrm{I}: 5,5 \mathrm{ml}$ de ácido para cada Ig de sólido. Utilizou-se uma solução IOM uma vez que a prata é solubilizada em solução $8 \mathrm{M}$ de ácido nítrico [13]. Essa etapa foi realizada com intenção de verificar se ainda existiam metais não solubilizados na etapa anterior (lixiviação em água régia). Após a filtragem do resíduo sólido, o licor foi analisado por ICP-OES visando novamente quantificar os metais presentes.

Os resíduos não lixiviados foram secos em estufa, $60^{\circ} \mathrm{C}$ por $48 \mathrm{~h}$, pesados para cálculo do balanço de massa $\mathrm{e}$ então encaminhados para análise de perda ao fogo.

\subsubsection{Caracterização com água régia invertida}

O lote $C$ foi selecionado com o intuito de verificar se o processo convencional de lixiviação por agua régia foi eficaz para a completa solubilização dos metais. Escolheu-se o processo de água régia invertida $\left(\mathrm{IHCl} 3 \mathrm{HNO}_{3}\right)$ por ser aplicado em laboratórios de análises químicas para abertura de amostras sólidas para quantificação de metais por ICP.

Aproximadamente $5 \mathrm{~g}$ de amostra foi colocada em ácido nítrico na proporção $\mathrm{I}: 10,10 \mathrm{ml}$ de ácido para cada I $\mathrm{g}$ de amostra, e a solução permaneceu por $24 \mathrm{~h}$ a temperatura ambiente de aproximadamente $25^{\circ} \mathrm{C}$. Posteriormente adicionou-se ao mesmo béquer $17 \mathrm{~mL}$ de ácido clorídrico, mantendo a proporção de ácidos $\left(\mathrm{IHCl}: 3 \mathrm{HNO}_{3}\right)$. Essa solução foi então aquecida a $100{ }^{\circ} \mathrm{C}$ até evaporação dos ácidos. Como se verificou que ainda havia peças metálicas mais $30 \mathrm{~mL}$ dessa mistura de ácidos foi adicionada e prosseguiu-se com a evaporação até restar líquido suficiente apenas para cobrir o sólido.

Essa solução foi filtrada com papel de filtro quantitativo de filtragem rápida em um balão volumétrico de $250 \mathrm{ml}$. Foi utilizado cerca de $40 \mathrm{~mL}$ da mistura de ácidos com água deionizada $(I: I)$ para lavar o papel de filtro com o objetivo de garantir que todo o metal solubilizado foi direcionado ao balão, adicionou-se ainda $20 \mathrm{~mL}$ de $\mathrm{HCl}$ e o restante do volume foi completado com água deionizada. O papel de filtro mais resíduo foi lavado com água deionizada em abundância e seco em estufa em $60^{\circ} \mathrm{C}$ por $48 \mathrm{~h}$. Após esse período pesou-se e fez-se balanço de massa.

Essa solução do balão volumétrico foi novamente filtrada em papel de filtro quantitativo de filtragem lenta uma vez que verificou-se a formação de precipitado. $O$ líquor previamente diluído foi novamente filtrado em papel de filtro de separação de fases. Encontrou-se uma massa de $0,0864 \mathrm{~g}$ de sólido precipitado, que foi caracterizado por EDS. Por fim, a concentração dos metais foi determinada utilizando ICP-OES.

\subsection{Perda ao Fogo e Composição das Pcis}

O resíduo remanescente da lixiviação em ácido nítrico foi colocado em navícula de cerâmica previamente pesada e levado ao forno a $800^{\circ} \mathrm{C}$ por Ih. Após resfriamento, a navícula foi novamente pesada e, após descontar a massa da navícula, tem-se que a diferença de massa entre o resíduo inicial e final corresponde a parte orgânica que evaporou e, portanto, representa a fração polimérica presente nas placas. Já o que restou na navícula corresponde à fração cerâmica, parte inorgânica [14].

As frações de cerâmicos, polímeros e metais foram determinadas pelas Equações I e 2:

$$
\begin{aligned}
& L A=(M) \\
& P F=(P)
\end{aligned}
$$

Onde LA significa Lixiviação em água régia; PF Perda ao fogo; $M$ refere-se à fração metálica; $P$ à fração polimérica. $A$ fração cerâmica foi determinada a partir das frações $\mathrm{M}$ e $\mathrm{P}$ [13].

\subsection{Cálculos Financeiros}

Os cálculos financeiros para avaliar o valor de venda dos metais analisados foram feitos baseados nas tabelas London Bullion Market Association e London Metal Exchange (LME) que possuem a cotação da tonelada de cada um dos metais analisados nesta pesquisa.

\section{RESULTADOS E DISCUSSÃO}

\section{I Análise no Estereoscópio}

Após a moagem observou-se perdas de massa decorrentes do manuseio do material no moinho e possíveis perdas em transporte de 2,75\% em média, sendo 2,5\% para o lote $\mathrm{A}, \mathrm{I}, 8 \%$ para o lote $\mathrm{B}, 3,0 \%$ para o lote $\mathrm{Ce}$ $3,2 \%$ para o lote $D$.

Nas imagens observadas (Figura 6-9) é possível observar partes metálicas visíveis tanto totalmente liberadas na amostra como associadas às outras camadas da placa. Segundo Reuter et al. [15] mesmo com algumas peças com materiais associados essa granulometria é eficiente para liberar os metais para a lixiviação ácida.

\subsection{Lixiviação Ácida das PCls}

\subsection{Caracterização com água régia, $\mathrm{HNO}_{3} \mathrm{e}$ perda ao fogo}

Após a sequência de lixiviações e ensaio de perda ao fogo foi possível determinar a composição das frações polimérica, cerâmica e metálica de cada lote de $\mathrm{PCls}$ estudados utilizando as equações de balanço de massa [8] (Figura I0). 


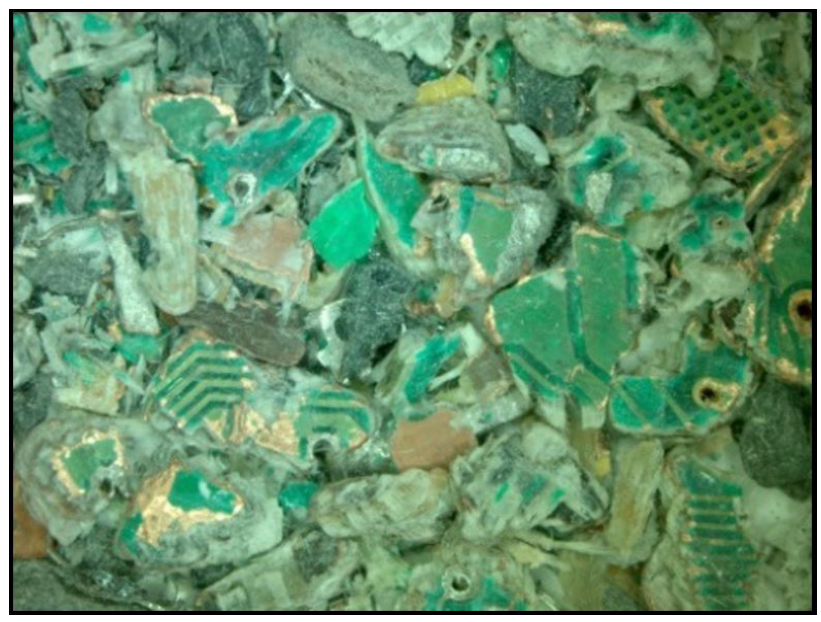

Figura 6. Lote A cominuido.

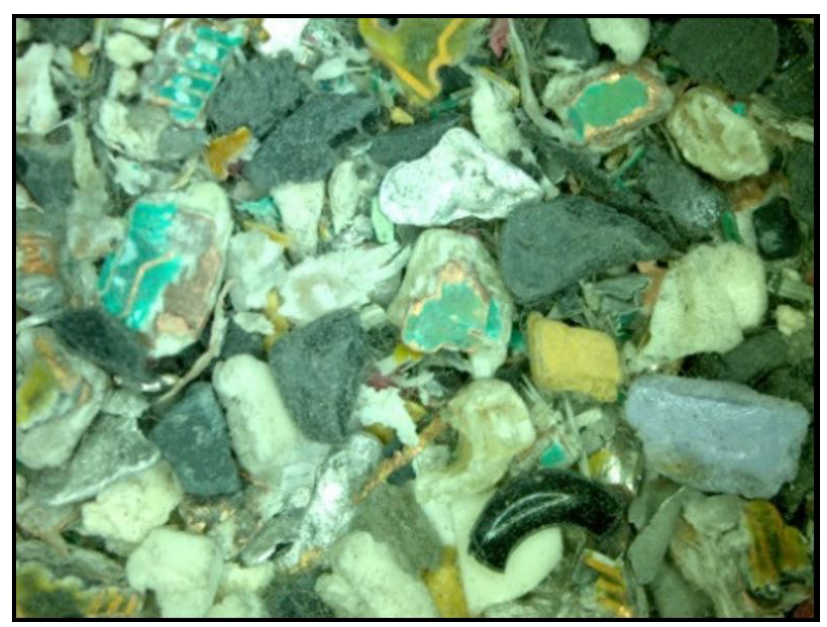

Figura 7. Lote B cominuido.

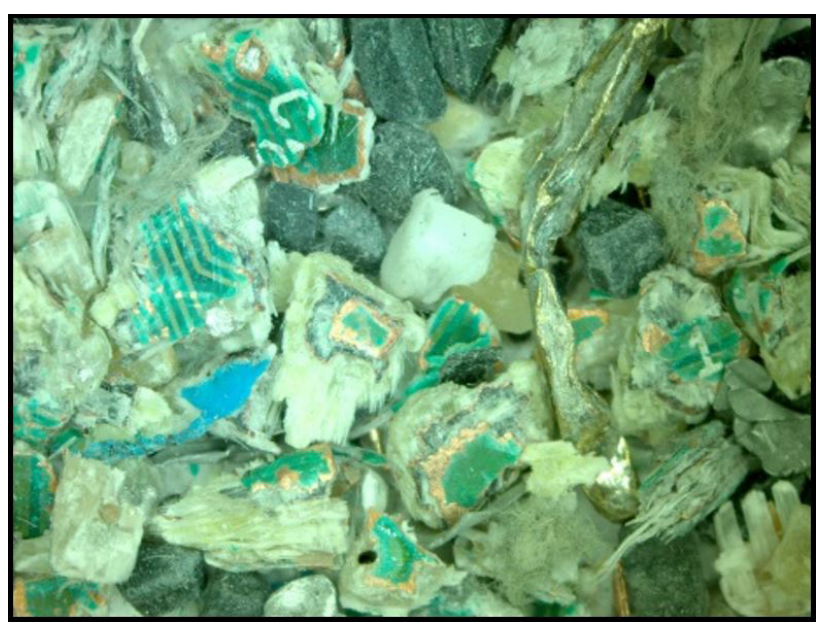

Figura 8. Lote $\mathrm{C}$ cominuido.

Verificou-se que o lote A estudado possui $33,58 \%$ em massa de metais, $37,89 \%$ de fração cerâmica e $28,52 \%$ de fração polimérica. O lote B possui $42,01 \%$ em massa de metais, $27,6 \%$ de fração cerâmica e $30,4 \%$ de

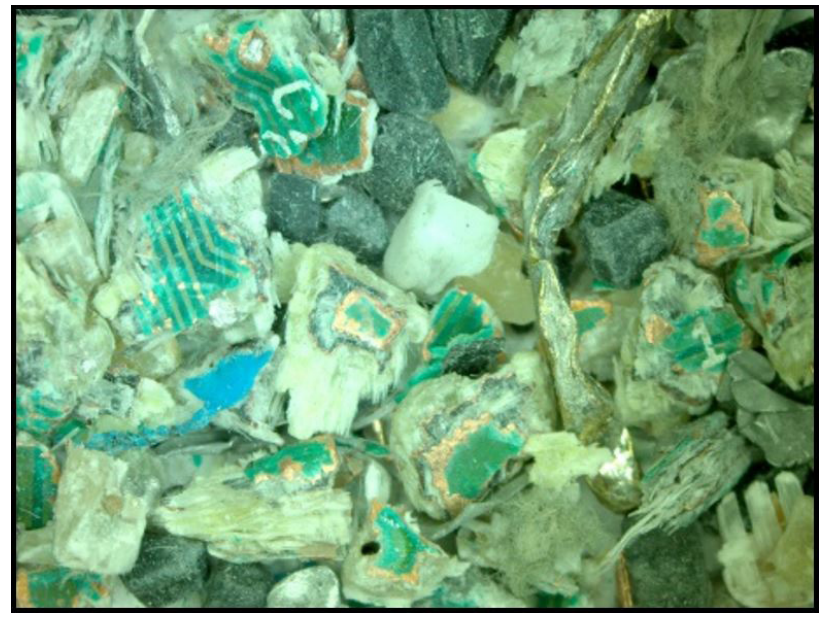

Figura 9. Lote D cominuido.

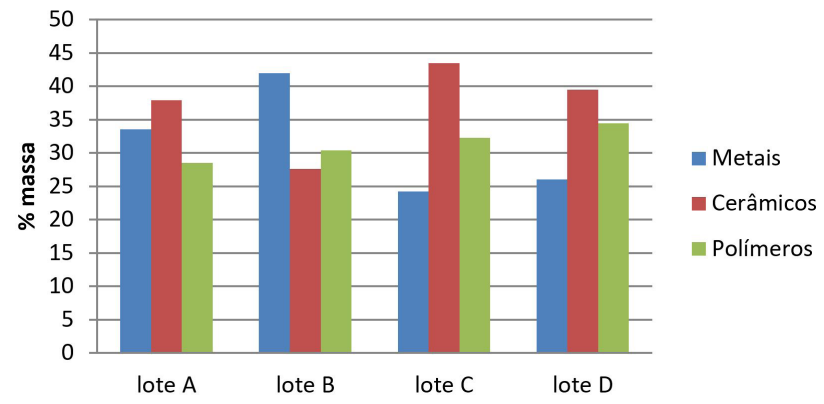

Figura 10. Gráfico de \% massa de cada fração nos lotes.

fração polimérica. O lote $C 24,27 \%$ em massa de metais, $43,46 \%$ de fração cerâmica e $32,27 \%$ de fração polimérica. E, o lote D $26,04 \%$ em massa de metais, $39,5 \%$ de fração cerâmica e $34,46 \%$ de fração polimérica. Segundo Yamane e Moraes et al, 20II [8] para computadores foram encontrado $45 \%$ metais, $27 \%$ polímeros e $28 \%$ cerâmicos. Já Veit et al. 2006 [9] encontrou também para placas de computadores $40 \%$ metais $30 \%$ cerâmicos e $30 \%$ de polímeros, em média. Portanto, apenas o lote $B$ ficou próximo desses resultados encontrados, os outros lotes possuem porcentagem de metais menor que encontrado na literatura. Esse se assemelha mais aos resultados já encontrados, pois é composto de placas mães antigas, um tipo de PCB mais comum nos resíduos eletroeletrônicos e possivelmente o utilizado nesses estudos.

\subsubsection{Caracterização usando água régia invertida}

Após os resultados do ensaio de água regia invertida foi possível por balanço de massa calcular a porcentagem de metais do lote $C$ analisando a diferença de massa entre o material colocado para digestão e o material retido no filtro. Encontrou-se um valor de $43,5 \%$ de metais. Comparando com o resultado do balanço de massa encontrado para a caracterização em água régia $(24,27 \%$ em massa de metais) percebe-se uma grande diferença. Porém, percebe-se que esse valor não representa apenas a fração metálica pois 
verificou-se a solubilização da resina, provavelmente devido a temperatura do experimento. As resinas mais utilizadas em PCBs são resina epoxy e resina fenólica e é possível haver solubilização de ambas nas condições do processo [16]. Essa rota de caracterização foi descartada, portanto, devido a solubilização da resina, o que compromete os resultados. Além disso essa rota apresenta maior utilização de reagentes, energia e tempo.

\subsection{Analise dos Metais por ICP-OES}

A porcentagem em massa dos metais presentes em cada lote foi calculada a partir dos resultados obtidos com a análise de ICP-OES da lixiviação em água régia. Os valores estão apresentados na Tabela I.

Valores semelhantes aos vistos na Tabela I também foram encontrados por outros autores. Park e Fray [7] encontraram $0,025 \%$ de ouro, $16 \%$ de cobre, $3 \%$ de estanho, $2 \%$ de chumbo e $5 \%$ de ferro. Já Tuncuk et al. [I] encontrou $0,01 \%$ de ouro, $18,5 \%$ de cobre, $4,9 \%$ de estanho, 2,7\% de chumbo e 2, $1 \%$ de ferro. Yamane et al. [8] encontraram $0,16 \%$ de prata, $0,13 \%$ de ouro, $20,19 \%$ de cobre, $8,83 \%$ de estanho, $5,53 \%$ de chumbo e $7,33 \%$ de ferro. Já Kasper et al. [10] encontraram 0,05\% de prata, $0,09 \%$ de ouro, $37,81 \%$ de cobre, $2,55 \%$ de estanho, $1,23 \%$ de chumbo e $4.85 \%$ de ferro.

Opostamente ao que sugere Petter et al. [17], a lixiviação em água régia mostrou ser suficiente para solubilizar os metais presentes na placa inclusive a prata, pois a lixiviação em ácido nítrico resultou em porcentagens massa de metais menores que $0,1 \%$ e para prata não houve solubilização.

O resultado está próximo do obtido por balanço de massa $(33,58 \%, 42,01 \%, 24,27 \%, 26,04 \%$ massa de metais dos lotes $A, B, C$ e $D$ respectivamente). Foi encontrada para os lotes $A, C$ e D uma maior porcentagem de metais por ICP-OES provavelmente devido à heterogeneidade das amostras e possíveis imprecisões nas pesagens e manipulações para cálculo de balanço de massa. Além disso, pode haver a presença de outros metais que não foram identificados na análise química por ICP-OES, no caso do lote $B$, em que se encontrou uma maior porcentagem metálica no balanço de massa.

Observa-se que todos os lotes de placas continham PCls que não são lead free, pois observa-se a presença de até I,46\% de chumbo. Isso era esperado já que a norma RoHS lead free, uma diretiva europeia de 2006 que proíbe que o chumbo seja usado no processo de fabricação, é relativamente recente e, algumas das placas usadas neste estudo são de equipamentos antigos.

Comparando as concentrações encontradas dos metais para o lote $C$ utilizando-se água régia e água régia invertida percebe-se que foram encontradas concentrações menores, porém próximas de todos os metais na água régia invertida, com exceção do bário $(0,2234 \%$ de diferença), cálcio (I,39\%) e ferro (3\%).

\subsection{Valorização}

O metal com maior porcentagem massa da placa em todos os lotes é o cobre. Em 2013 o preço do cobre em média foi 7.926,00 U\$/t [I8]. Considerando que haja recuperação de $100 \%$ do cobre no lote seria possível retirar 227,8kg de cobre o equivalente a 1.5 I8,74 dólares. As reservas brasileiras de minério de cobre possuem um teor médio de $0,8 \%$ de cobre, já no Chile, que detêm $32,7 \%$ das reservas mundiais esse teor pode chegar em até I,5\%[18]. Portanto há maior disponibilidade de cobre na placa do que no minério, o que tem influenciado o grande número de estudos na área $[7,8,12,14,17]$.

Já em relação ao ouro foi encontrado para o lote A uma porcentagem em massa de $0,06 \%$, o equivalente a $24.760,06$ dólares se $100 \%$ fosse recuperado. As reservas brasileiras possuem um teor de ouro de 0,0002\% aproximadamente [18]. Portanto, uma placa pode conter até 300 vezes mais ouro que seu minério.

Tabela I. Porcentagem em massa de cada metal nos lotes estudados a partir dos ensaios de lixiviação ácida

\begin{tabular}{lccccc}
\hline \multicolumn{1}{c}{ Metal } & Lote $\mathbf{A}^{\prime}$ & Lote $\mathbf{B}^{\prime}$ & Lote $\mathbf{C}^{\prime}$ & ${\text { Lote } \mathbf{C}^{2}}$ & Lote $^{\prime}$ \\
\hline Prata & 0,03 & 0,019 & 0,062 & $0,03 / 2$ & 0,033 \\
Alumínio & 0,06 & 7,5 & 3,026 & 2,73 & 3,55 \\
Ouro & 0,06 & 0,015 & 0,0205 & 0,00853 & 0,012 \\
Bário & 0,07 & 0,025 & 0,0246 & 0,248 & 0,015 \\
Cálcio & 0,07 & 0,23 & 0,07 & 1,46 & 0,0949 \\
Cobalto & 0,01 & 0 & 0,0157 & 0,01 & 0 \\
Cobre & 26,4 & 22,78 & 16,67 & 15,98 & 14,28 \\
Ferro & 2,1 & 0,026 & 0 & 2,996 & 3,73 \\
Níquel & 2,24 & 0,084 & 0,352 & 0,972 & 0,46 \\
Chumbo & 1,46 & 0,288 & 0,87 & 1,015 & 0,87 \\
Estanho & 2,95 & 2,7 & 2,93 & 2,68 & 1,29 \\
Zinco & 2,69 & 5,38 & 0,842 & 0,858 & 2,63 \\
Total & 38,14 & 39,05 & 24,88 & 28,99 & 26,96 \\
\hline
\end{tabular}

'Lixiviação em água régia; ${ }^{2}$ Lixiviação em água régia invertida. 
Calcula-se que para 100\% dos metais recuperados nos lotes estudados seria possível obter para o lote $A$ $27.643,42$ dólares, para o lote $B$ 8.585,22 dólares, para o lote $C$ 10.187,76 dólares e para o lote $D$ 6.409, 17 dólares por tonelada.

No mercado brasileiro encontra-se uma média de preço no mercado de compra e vendas de sucata de 15.909,09 dólares por tonelada do lote A, 5.68I,8 dólares/t do lote $B, 5.727,09$ dólares/t do lote $C$ e 6. 136,36 dólares/t do lote $D$.

\section{CONCLUSÕES}

A partir da análise dos resultados concluiu-se que:

- O lote A estudado possui $33,58 \%$ em massa de metais, $37,89 \%$ de fração cerâmica e $28,52 \%$ de fração polimérica. O lote $B$ possui $42,01 \%$ em massa de metais, $27,6 \%$ de fração cerâmica e $30,4 \%$ de fração polimérica. O lote C $24,27 \%$ em massa de metais, $43,46 \%$ de fração cerâmica e $32,27 \%$ de fração polimérica. E, o lote $D 26,04 \%$ em massa de metais, $39,5 \%$ de fração cerâmica e $34,46 \%$ de fração polimérica;
- Os lotes estudados possuem placas que não são lead free;

- Verificou-se a presença de uma gama de metais, sendo os de maior interesse: cobre $(14,28-26,4 \%)$, estanho $(1,29-2,95 \%)$, ouro $(0,012-0,06 \%)$, alumínio $(0,06-7,5 \%)$, prata $(0,019-0,062 \%)$, zinco (0,842-5,38\%) e Ni (0,084-2,24\%);

- Podem ser recuperados para o lote A27.643,42 dólares, para o lote B 8.585,22 dólares, para o lote C 10.187,76 dólares e para o lote $D 6409,17$ dólares por tonelada se $100 \%$ dos metais fossem recuperados. A maior valor agregado encontrado para o lote A se dá devido à presença muito superior de ouro neste lote;

- A concentração de cobre e ouro é maior que nos minérios, influenciando estudos na área, destacando a importância da caracterização para processos futuros de reciclagem e recuperação das frações metálicas.

\section{Agradecimentos}

À FAPESP, processo 17412-0, CNPq e CAPES. Ao Instituto Federal do Espirito Santo.

\section{REFERÊNCIAS}

I Tuncuk A, Akcil A, Yazici EY, Devici H. Aqueous metal recovery techniques from e-scrap: hydrometallurgy in recycling. Minerals Engineering. 20I2;25(I):28-37.

2 United Nations Environment Programme. Call for global action on e-waste. Lisboa: UNEP; 2006

3 Baldé C.P., Forti V., Gray V., Kuehr R., Stegmann P. The global e-waste monitor - 2017: quantities, flows, and resources. Genebra: ITU.

4 Araújo MG, Magrini A, Mahler CF, Bilitewski B. A model for estimation of potential generation of waste electrical and electronic equipment in Brazil. Waste Management (New York, N.Y.). 20 12;32(2):335-342.

5 Robinson BH. E-waste: an assessment of global production and environmental impacts. The Science of the Total Environment. 2009;408(2):183-191.

6 Ongondo FO, Williams ID, Cherrett TJ. How are WEEE doing? A global review of the management of electrical and electronic wastes. Waste Management (New York, N.Y.). 201 I;4(3I):7I4-730.

7 Park YJ, Fray DJ. Recovery of high purity precious metals from printed circuit boards. Journal of Hazardous Materials. 2009;164:1152-II58.

8 Yamane LH, Moraes VT, Espinosa DCR, Tenório JAS. Recycling of WEEE: characterization of spent printed circuit boards from mobile phones and computers. Waste Management (New York, N.Y.). 201 I ;3 I (I 2):2553-2558.

9 Veit HM, Bernardes AM, Ferreira JZ, Tenório JAS, Malfatti CF. Recovery of copper from printed circuit boards scraps by mechanical processing and electrometallurgy. Journal of Hazardous Materials. 2006; 137(3): I 704-I 709.

10 Kasper AC, Berselli GBT, Freitas BD, Tenório JAS, Andréa M, Bernardes AM, et al. Printed wiring boards for mobile phones: characterization and recycling of copper. Waste Management (New York, N.Y.). 20 I I;3 I ( 2):2536-2545.

I I Marques AC, Cabrera JM, Fraga Malfatti CF. Printed circuit boards: a review on the perspective of sustainability. Journal of Environmental Management. 2013;131:298-306.

12 Zhang S, Forssberg E. Mechanical separation-oriented characterization of electronic scrap. Resources, Conservation and Recycling. 1997;21:247-269.

13 Vogel Al. Química analítica qualitativa. $5^{\text {a }}$ ed. São Paulo: Mestre Jou; 1992. 
14 Moraes V. Recuperação de metais a partir do processamento mecânico e hidrometalúrgico de placas de circuito impresso de celulares obsoletos. [doutorado]. São Paulo: Escola Politécnica, Universidade de São Paulo; 201 I.

15 Reuter MA, Hudson C, van Schaik A, Heiskanen K, Meskers C, Hagelüken C. Metal recycling: opportunities, limits, infrastructure - a report of the working group on the global metal flows to the international resource panel. Lisboa: UNEP; 2013.

I6 Li J, Shrivastava P, Gao Z, Zhang HC. Printed circuit board recycling: a state-of-the-art survey. IEEE Transactions on Electronics Packaging Manufacturing. 2004;27(I):33-42.

17 Oliveira PCF. Valorização de placas de circuito impresso por hidrometalurgia [Tese de doutorado]. Lisboa: Universidade Técnica de Lisboa; 2012.

18 Agência Nacional de Mineração. Departamento Nacional de Produção Mineral [página da internet]. Brasília: ANM; 2014 [citado em 2017 Março 2I]. Disponível em: http://www.dnpm.gov.br/

Recebido em: I Jun. 2018

Aceito em: 8 Nov. 2018 